\title{
Are Oaks Locally Adapted to Serpentine Soils?
}

\author{
Sara Branco*
}

\begin{abstract}
Serpentine soils are extreme habitats known to be involved in processes of local adaptation and speciation of plants. Here I use a greenhouse reciprocaltransplant experiment to compile baseline data for describing patterns of serpentine local adaptation in Quercus ilex subsp. ballota (Holm Oak). I also tested the role of mycorrhizal fungi on the establishment and growth of seedlings on serpentine and non-serpentine soil. Non-serpentine seedlings grew more than serpentine seedlings in all treatments. Plants grew more on non-serpentine soil and mycorrhizal fungi positively influenced seedling growth. I did not find evidence of better seedling performance in their home environment, suggesting the absence of local adaptation. However, I document significant growth differences between serpentine and nonserpentine seedlings, which suggest physiological differences between seedlings from these two soil origins.
\end{abstract}

\section{Introduction}

The process of local adaptation leads to the evolution of advantageous traits in local populations associated with particular environmental conditions (Williams 1966). Resident genotypes in each local population are expected to exhibit higher relative fitness on average in their original local habitat compared to genotypes originated elsewhere (Kawecki and Ebert 2004). Local adaptation has been recognized as an important mechanism maintaining genetic variation (Hedrick 1986), as well as a crucial player in initiating the divergence of incipient species (Schluter 2001, Turelli et al. 2001, Via 2001). Tests for patterns of local adaptation rely on good fitness estimates, a complex parameter that should consider multiple stages of the individual's life cycle (Charlesworth 1994). Fitness is difficult to estimate, particularly in long-lived organisms, leading to the use of less ideal parameters, such as biomass, as fitness surrogates.

Extreme habitats, such as deserts, hydrothermal vents, hot springs, hyper-saline waters, and serpentine soils - impose severe conditions on their inhabitants, and are thus attractive natural systems for evolutionary and ecological studies. Generally speaking, two strategies allow species to persist in extreme environments. One is plasticity, i.e., environment-dependent phenotypic expression (Bradshaw 1965) that confers constitutive tolerance. The other is specialization, which may range from locally adapted populations

\footnotetext{
*Committee on Evolutionary Biology, University of Chicago, 1025 East 57th Street, Culver Hall 402, Chicago, IL 60637; Field Museum of Natural History, 1400 South Lake Shore Drive, Chicago, IL 60605; Centro de Investigação de Montanha, Escola Superior Agrária, Instituto Politécnico de Bragança, Campus de Sta. Apolónia Apartado 1172, Bragança, Portugal; sbranco@uchicago.edu.
} 
(Williams 1966) with habitat-based discontinuous morphological and/or physiological variation (ecotypes; Turesson 1922) to endemic species that are obligately associated with their habitats and occur nowhere else.

Heterogeneous soil conditions have been documented as an important selective pressure for terrestrial plants that can be responsible for divergence and speciation (Kruckeberg 2002). Serpentine soils in particular are an ideal system to study patterns of local adaptation and phenotypic plasticity. These soils are characterized by a unique combination of chemical and physical parameters, including low essential macro- and micronutrients, an unbalanced $\mathrm{Ca}: \mathrm{Mg}$ ratio, and toxic concentrations of heavy metals like $\mathrm{Co}, \mathrm{Cr}, \mathrm{Mg}$, and Ni (Roberts and Proctor 1992). Serpentine sites have low plant productivity, depauperate floras and sparse plant cover, high rates of endemism, and vegetation types different from those of neighboring areas (Alexander et al. 2007, Baker et al. 1992, Brady et al. 2005, Brooks 1987). They are found worldwide and are patchily distributed, covering about $1 \%$ of the earth's surface (Proctor 1999, Roberts and Proctor 1992). The evolutionary and ecological significance of serpentine soils has been extensively studied in plants. Adaptive divergence in species found in both serpentine and non-serpentine soils has been demonstrated via reciprocal transplant experiments both in field and greenhouse conditions (e.g., Kruckeberg 1950, Sambatti and Rice 2006, Wright 2007, Wright et al. 2006). These studies subjected plants from serpentine and non-serpentine populations to native and non-native soil and described plants as having higher fitness when grown in their native soil, indicating the existence of serpentine local adaptation.

The vast majority of vascular plants (including plants growing in serpentine soils) are associated with symbiotic mycorrhizal fungi (Smith and Read 2008). These fungi mediate nearly all water and nutrient uptake by host plant roots, providing a larger absorption area for root systems and enabling plants to obtain water and nutrients when these resources are not readily available (Smith and Read 2008). In return, fungi obtain sugars, essential for their subsistence. Ectomycorrhizal (ECM) fungi are known to play an important role in plant establishment under stressful conditions (Jentschke and Godbold 2000, Panaccione et al. 2001, Roberts and Proctor 1992) because they can filter toxic components that might occur in the soil, preventing their accumulation in plants (Hartley et al. 1997). This relationship may be particularly important in serpentine environments, given their typically high concentrations of heavy metals such as nickel. To this extent, ECM fungi may play an especially significant role in the establishment and survivorship of seedlings on serpentine soils, and knowledge of the effects of native fungal ECM fungal communities on plant fitness at different stages of life history are therefore important for a full understanding of the patterns of serpentine local adaptation in mycorrhizal plants.

This study is a preliminary effort to gather baseline data on local adaptation to serpentine soils in Quercus ilex subsp. ballota (Desf) Samp (Holm Oak), a widespread Mediterranean evergreen oak and the only tree found to 
colonize serpentine sites in northeastern Portugal. I conducted a greenhouse reciprocal transplant experiment and measured serpentine and non-serpentine seedling establishment and early growth in native and non-native soil with and without the native ECM fungal communities. As comprehensive studies on local adaptation require fitness estimates, which are extremely difficult to measure for long-lived organisms such as oak trees, I based this study on seedling growth data. I expected to find seedlings to show more growth on their native soil, suggesting serpentine local adaptation. I also predicted mycorrhizal fungi to enhance seedling performance in general and seedlings to show a greater growth response on serpentine compared to nonserpentine soil in the presence of fungi (i.e., plants relying more on fungi in serpentine soil).

\section{Methods}

\section{Experimental set-up}

Soil. I collected serpentine and non-serpentine soil from two Holm Oak forests in the Bragança region (Portugal), Rabal (N41 ${ }^{\circ} 52.262$, W006 ${ }^{\circ} 44.682$ ) and Serra da Nogueira $\left(\mathrm{N} 41^{\circ} 47.965\right.$, W006 53.924$)$. These two forests were approximately $10 \mathrm{~km}$ apart. Upon collection, serpentine and non-serpentine soils were separately mechanically homogenized using a concrete mixer.

Soil analyses were conducted for both the Serra da Nogueira and Rabal sites in 2005. I collected four soil samples in each forest, with each sample consisting of the combination of 5 soil sub-samples collected $5 \mathrm{~m}$ apart. Standard soil parameters, macro- and micronutrients, and heavy metal content were analyzed for each sample $(\mathrm{pH}, \mathrm{N}, \mathrm{C}, \mathrm{Al}, \mathrm{P}, \mathrm{K}, \mathrm{Ca}, \mathrm{Mg}, \mathrm{B}, \mathrm{Mn}$, $\mathrm{Zn}, \mathrm{Cu}, \mathrm{Fe}, \mathrm{Pb}, \mathrm{Ni}, \mathrm{Cr}, \mathrm{Cd}, \mathrm{NO}_{3}-\mathrm{N}$, cation exchange capacity, percent base saturation for $\mathrm{K}, \mathrm{Mg}$, and $\mathrm{Ca}$ ). Analyses were conducted at the University of Massachusetts Soil and Plant Tissue Testing Laboratory (Amherst, MA, USA), except for $\mathrm{C}$ and $\mathrm{N}$, which were performed at (Argonne National Laboratory Argonne, IL,USA), and $\mathrm{pH}$, which was measured in the Soil Laboratory of Escola Superior Agrária de Bragança (Portugal). I compared the two soil types using a standard one-way ANOVA (implemented in R Development Core Team, version 2.6.2).

Acorns. I collected Holm Oak acorns from a serpentine site (Rica Fe, $\mathrm{N} 41^{\circ} 49.66{\left.\mathrm{~W} 006^{\circ} 45.43\right)}$ and a non-serpentine site (Quintas de Seara, $\mathrm{N} 41^{\circ} 45.45 \mathrm{~W} 006^{\circ} 43.27$ ) approximately $10 \mathrm{~km}$ apart in Bragança, Portugal, in November 2006. Acorns were collected from the same forests as the soils; however, because 2006 was a very wet year, most acorns were not in good condition and failed to germinate. As a result, I used acorns from neighboring serpentine and non-serpentine forests (approximately $10 \mathrm{~km}$ away). Acorns were stratified until the beginning of the experiment.

Reciprocal-transplant experiment. Acorns were germinated in sand in February 2007. In May 2007, I transplanted the seedlings to 1-L pots with sterile and non-sterile serpentine and non-serpentine soil. Sterile soil was generated using an autoclave $\left(45 \mathrm{~min}, 121^{\circ} \mathrm{C}, 1 \mathrm{~kg} / \mathrm{cm}^{2}\right)$. This sterile soil was used for 
growing the control seedlings so that the importance of ECM fungi on seedling establishment and growth on serpentine soil could be assessed.

During the transplant, I trimmed the root system of each seedling to its shoot length and excised vestigial acorns to induce mycorrhizal infection and minimize maternal effects. I also visually inspected the seedling's roots to assure that they were not already infected with ECM fungi. Root tips showed a very homogenous morphology, with abundant root hairs and no Hartig nets, indicating they were free of ECM fungal infection. Furthermore, using molecular techniques, I did not find ECM fungal DNA in 6 random root tips. I used the fungal specific primers ITS1F and ITS4 (Gardes and Bruns 1996, White et al. 1990) and the PCR and sequencing protocols of Avis et al. (2003).

Seedlings were kept in the greenhouse facilities of Escola Superior Agrária de Bragança at $26^{\circ} \mathrm{C}$ and $75 \%$ humidity, and were manually watered with no fertilization weekly through September 2007, when measurements were taken. Because this was an ongoing experiment, I did not harvest the seedlings at that time. Instead, I transplanted the seedlings to other soil types. During this procedure, I visually inspected all root systems, and it was very clear that all the seedlings grown on non-sterile soil were colonized by ECM fungi (there was fungal tissue covering the root tips and, in some cases, abundant mycelium in the soil). Plants grown on sterile soil showed homogenous naked roots similar to the ones described in the beginning of the experiment, indicating no ECM fungal infection. These observations indicate that the autoclaving protocol was effective in eliminating the ECM fungi present in the soil and that there were no fungal contaminations during the time of the experiment.

\section{Seedling early growth measurements}

Oaks are long-lived plants, and their fitness is difficult to estimate. Here, I followed many authors' approach in using biomass as a surrogate for fitness (e.g., Jenkinson 1977, Wright 2007). Because this was an ongoing experiment and the plants were not harvested in the end, seedling biomass was not measured directly. I tested seedling stem height, number of leaves, root length, number of internodes and collar diameter as surrogates for plant biomass by regressing the dried weight of 25 seedlings to each of these parameters. I found seedling stem height to be best correlated with total dry seedling weight (regression analysis performed in $\mathrm{R}$ [R Development Core Team, version 2.6.2]; $\left.R^{2}=0.695, P<0.001, n=25\right)$. Stem heights were first measured in the beginning of the experiment (in May 2007) and then in September 2007, when seedlings were 8 months old.

\section{Statistical analysis}

Seedling stem heights measured in September 2007 and relative growth rate $(\mathrm{RGR}=[$ stem height September - stem height May $] /$ number of days experiment run) were square root transformed to meet ANOVA assumptions and compared across treatments using a two-way ANOVA analysis with 
acorn origin (serpentine and non-serpentine) and soil type (serpentine, nonserpentine, sterile serpentine, sterile non-serpentine) as factors. I used type III sums of squares (Yates 1934) to account for unbalanced sampling. The effect of ECM fungi in serpentine and non-serpentine soil and on serpentine and non-serpentine plants was tested using a priori contrasts (Sokal and Rohlf 1995). Adjustments were made for unequal sample size and nonorthogonality (Dunn-Sidák method). I also conducted two-way ANOVA analyses on the data from non-sterile soil and sterile soil separately.

Differences in seedling stem height measured in the beginning of the experiment (May 2007) were tested with a Kruskal Wallis rank sum test since data violated ANOVA assumptions of homogeneity of variances and residual normality even after transformation.

All analyses were implemented in $\mathrm{R}$ ( $\mathrm{R}$ Development Core Team, version 2.6.2).

\section{Results}

Soil analyses show that the serpentine and non-serpentine soils were different. The serpentine soil showed the typical low $\mathrm{Ca}: \mathrm{Mg}$ ratio and high levels of metals (Table 1).

Only 7 out of the 209 seedlings died during the 6 months of exposure to serpentine and non-serpentine soil (Table 2). This result indicates that both

Table 1. Average soil chemical composition of serpentine and non-serpentine (with standard deviations; $\mathrm{ppm}=$ parts per million; $\% \mathrm{BS}=$ percent base saturation, $*=$ significant $P$ value of the one-way ANOVA analysis after a sequential Bonferroni correction).

\begin{tabular}{lcc} 
Soil parameter & Serpentine soil & Non-serpentine soil \\
\hline $\mathrm{Al}(\mathrm{ppm})$ & $12.3( \pm 5.4)$ & $28.8( \pm 0.7)$ \\
$\mathrm{B}(\mathrm{ppm})^{*}$ & $1.1( \pm 0.1)$ & $0.3( \pm 0.0)$ \\
$\mathrm{C}(\%)^{*}$ & $10.7( \pm 1.6)$ & $1.6( \pm 0.2)$ \\
$\mathrm{Ca}(\% \mathrm{BS})$ & $15.9( \pm 2.0)$ & $42.9( \pm 3.3)$ \\
$\mathrm{Ca}(\mathrm{ppm})^{*}$ & $1014.3( \pm 89.5)$ & $1349.8( \pm 83.4)$ \\
$\mathrm{Ca} / \mathrm{Mg} *$ & $0.4( \pm 0.0)$ & $2.0( \pm 0.0)$ \\
$\mathrm{Cation} \mathrm{exchange} \mathrm{capacity*}$ & $32.3( \pm 2.1)$ & $16.6( \pm 0.9)$ \\
$\mathrm{Cd}(\mathrm{ppm})^{*}$ & $0.38( \pm 0.1)$ & $0.0( \pm 0.0)$ \\
$\mathrm{Cr}(\mathrm{ppm})^{*}$ & $0.5( \pm 0.1)$ & $0.2( \pm 0.1)$ \\
$\mathrm{Cu}(\mathrm{ppm})$ & $0.1( \pm 0.1)$ & $0.4( \pm 0.1)$ \\
$\mathrm{Fe}(\mathrm{ppm})^{*}$ & $23.3( \pm 4.8)$ & $6.9( \pm 0.8)$ \\
$\mathrm{K}(\% \mathrm{BS})^{*}$ & $0.7( \pm 0.2)$ & $2.6( \pm 0.40$ \\
$\mathrm{K}(\mathrm{ppm})^{*}$ & $81.3( \pm 21.7)$ & $154.5( \pm 26.2)$ \\
$\mathrm{Mg}(\% \mathrm{BS})^{*}$ & $60.4( \pm 5.7)$ & $22.4( \pm 8.6)$ \\
$\mathrm{Mg}(\mathrm{ppm})^{*}$ & $2378.8( \pm 327.6)$ & $430.5( \pm 171.8)$ \\
$\mathrm{Mn}(\mathrm{ppm})$ & $180.6( \pm 44.0)$ & $117.8( \pm 7.1)$ \\
$\mathrm{N}(\%)$ & $0.5( \pm 0.1)$ & $0.2( \pm 0.0)$ \\
$\mathrm{Ni}(\mathrm{ppm})^{*}$ & $29.8( \pm 8.1)$ & $1.0( \pm 0.4)$ \\
$\mathrm{NO}_{3}-\mathrm{N}(\mathrm{ppm})$ & $7.8( \pm 3.3)$ & $1.3( \pm 0.0)$ \\
$\mathrm{P}(\mathrm{ppm})^{*}$ & $27.3( \pm 3.9)$ & $7.5( \pm 2.1)$ \\
$\mathrm{Pb}(\mathrm{ppm})$ & $31.7( \pm 0.3)$ & $30.5( \pm 0.0)$ \\
$\mathrm{pH} \mathrm{Zn}^{*}$ & $6.1( \pm 0.1)$ & $5.3( \pm 0.1)$ \\
$\mathrm{Zn}(\mathrm{ppm})$ & $1.9( \pm 0.9)$ & $1.1( \pm 0.5)$ \\
\hline
\end{tabular}


serpentine and non-serpentine plants can tolerate non-native soil under greenhouse conditions, at least during their first months of existence. However, I found significant differences in seedling growth across the different treatments. Analyses on seedling stem height and relative growth rate provided identical results, so here I report only seedling stem height results. Overall, non-serpentine seedlings grew more and faster than serpentine seedlings (Table 3, Figs. 1 and 2), plants grew less and slower on serpentine soil compared to non-serpentine soil (Fig. 1, Table 3), and seedlings performed poorly in sterile soil (Table 3 ).

The two-way ANOVA with the four soil types as factors showed that both plant origin and soil type were significant terms in the model

Table 2 . Number of Quercus ilex subsp. ballota (Holm Oak) seedlings transplanted to each of the four soil treatments. $\dagger=1$ seedling died during the experiment; $\uparrow \dagger=2$ seedlings died during the experiment.

\begin{tabular}{lccc} 
& Serpentine plants & Non-serpentine plants & Total \\
\hline Serpentine soil & $42 \dagger \dagger$ & $42 \dagger$ & 84 \\
Non-serpentine soil & $43 \dagger$ & $44 \dagger$ & 87 \\
Sterile serpentine soil & $8 \dagger \dagger$ & 10 & 18 \\
Sterile non-serpentine soil & 9 & 11 & 20 \\
Total & 102 & 107 & \\
\hline
\end{tabular}

Table 3. Average stem height (in $\mathrm{cm}$ ) for serpentine and non-serpentine seedlings grown in each of the four treatments (with standard deviations).

\begin{tabular}{lcc} 
& Serpentine plants & Non-serpentine plants \\
\hline Serpentine soil & $3.26( \pm 0.62)$ & $3.77( \pm 0.66)$ \\
Non-serpentine soil & $3.70( \pm 0.54)$ & $4.35( \pm 0.75)$ \\
Sterile serpentine soil & $2.54( \pm 0.28)$ & $3.57( \pm 0.44)$ \\
Sterile non-serpentine soil & $2.70( \pm 0.54)$ & $3.12( \pm 0.52)$ \\
\hline
\end{tabular}

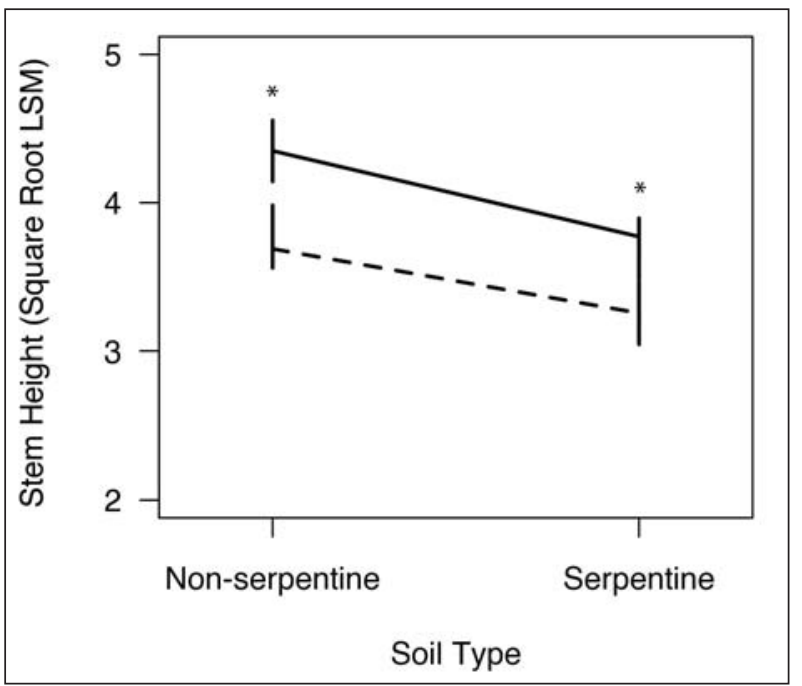

Figure 1. Least square means (LSM) and 95\% confidence intervals of serpentine and non-serpentine Quercus ilex subsp. ballota (Holm Oak) seedlings' stem height measurements on the non-sterile soil treatments (data squareroot transformed). Solid line = nonserpentine seedlings; dashed line = serpentine seedelings; $*=$ averages significantly different. 
(Table 4), indicating differences in growth between serpentine and nonserpentine plants and between plants on serpentine and non-serpentine soil. However, the interaction term was not significant, indicating the effect of plant origin was not dependent on soil type and vice versa. The a priori contrasts revealed growth differences between the two plant origins in both serpentine and non-serpentine soil, but revealed no significant differences between serpentine seedling growth in serpentine and non-serpentine soil or between non-serpentine seedling growth in serpentine and non-serpentine soil (Table 4).

The two-way ANOVA analysis on non-sterile soil growth revealed soil type and acorn origin as significant factors, but a non-significant interaction (Fig. 1 and Table 5). There was reduced growth on sterile soil compared to non-sterile soil (Table 3 ). On sterile soil, non-serpentine plants still tended to grow more and faster compared to serpentine. However, growth was only significantly different on serpentine soil, as soil type was not a significant factor in the analysis (Fig. 2, Table 6).

Figure 2. Least square means (LSM) and $95 \%$ confidence intervals of serpentine and non-serpentine Quercus ilex subsp. ballota (Holm Oak) seedlings' stem height measurements on the sterile soil treatments (data square-root transformed). Solid line $=$ non-serpentine seedlings; dashed line $=$ serpentine seedlings; $*=$ averages significantly different.

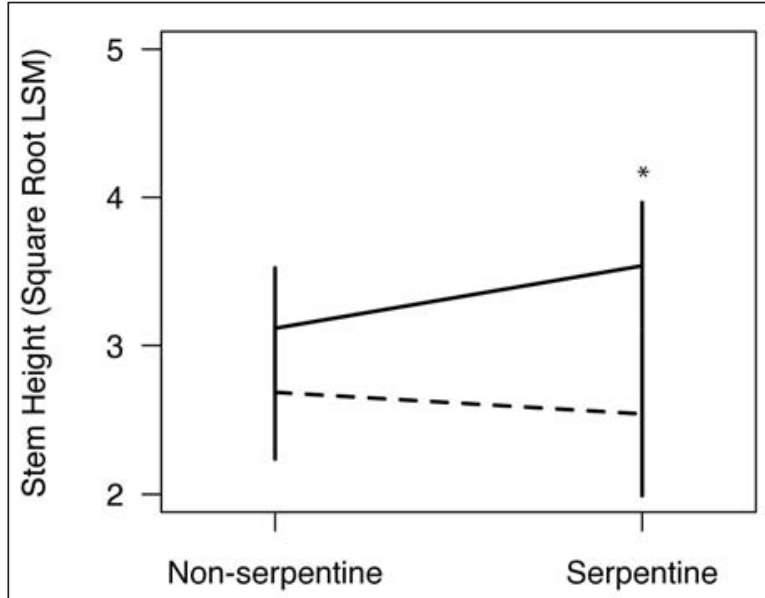

Soil Type

Table 4. Two-way ANOVA on seedling stem heights with type III sums of squares results (two seedling origins and four soil types) including the a priori test results $(\alpha=0.013)$. ${ }^{*}=$ signifi- $^{-}$ cant factor.

\begin{tabular}{lrrrc} 
& d.f. & \multicolumn{1}{c}{ SS } & \multicolumn{1}{c}{$F$} & $P$ \\
\hline Soil & 3 & 28.83 & 21.13 & $<0.013^{*}$ \\
Acorn & 1 & 11.97 & 25.43 & $<0.013^{*}$ \\
Soil x Acorn & 3 & 0.96 & 0.68 & 0.567 \\
Non-serpentine vs serpentine plants on non-serpentine soil & 1 & 29.77 & 63.21 & $<0.013^{*}$ \\
Non-serpentine vs serpentine plants on serpentine soil & 1 & 10.79 & 22.91 & $<0.013^{*}$ \\
Non-serpentine plants on non-serpentine vs serpentine soil & 1 & 17.42 & 36.99 & 0.99 \\
Serpentine plants on non-serpentine vs serpentine soil & 1 & 13.13 & 27.88 & 0.99 \\
Residuals & 196 & 92.25 & & \\
\hline
\end{tabular}


The Kruskal Wallis rank sum test analysis performed on the seedling stem height in the beginning of the experiment (May 2007) revealed significant differences between heights of serpentine and non-serpentine seedlings, with non-serpentine plants being taller $\left(\chi^{2}=287.6979\right.$, d.f. $\left.=1, P<0.05\right)$.

\section{Discussion}

There are numerous examples of serpentine local adaptation in plants (e.g., Kruckeberg 1950, Sambatti and Rice 2006, Wright 2007, Wright et. al. 2006). In these cases, serpentine ecotypes exhibit higher fitness when growing on serpentine soil, indicating adaptation to the low $\mathrm{Ca} / \mathrm{Mg}$ ratio and high levels of heavy metals.

Holm Oak is a widespread oak and the only tree able to grow on serpentine soils in northeastern Portugal, though it is not known if serpentine populations are locally adapted. The greenhouse results reported here are a first effort to provide a baseline for determining the existence of serpentine local adaptation in this oak. Although seedling early growth under greenhouse conditions may not be a good measure of plant fitness, making it difficult to draw conclusions on serpentine local adaption, seedlings did not grow more on their native soil (Fig. 1), suggesting lack of local adaptation. However, given the extreme chemical and physical conditions of serpentine soils, slower plant growth may be selected for, and very often plant adaptation to serpentine soils includes slow growth and reduced plant stature (Brady et. al. 2005). Nevertheless, the significant growth differences reported here suggest physiological variation between seedlings originating on serpentine versus non-serpentine soil. Non-serpentine seedlings grew consistently and significantly taller and faster than serpentine seedlings (Figs. 1 and 2, Table 3), even when exposed to serpentine soil.

An interesting example where growth was used to describe serpentine local adaptation in a tree is the study on Pinus ponderosa P.\&C. Lawson

Table 5. Two-way ANOVA on seedling stem height results (two seedling origins and two nonsterile soil types). ${ }^{*}=$ significant factor.

\begin{tabular}{lcrrc} 
& d.f. & \multicolumn{1}{c}{ SS } & \multicolumn{1}{c}{$F$} \\
\hline Soil type & 1 & 10.73 & 20.69 & $<0.05^{*}$ \\
Acorn origin & 1 & 14.53 & 28.01 & $<0.05^{*}$ \\
Soil x acorn & 1 & 0.22 & 0.43 & 0.51 \\
Residuals & 85.08 & 164.00 & & \\
\hline
\end{tabular}

Table 6. Two-way ANOVA on seedling stem height results (two seedling origins and two sterile soil types). * = significant factor.

\begin{tabular}{lcccc} 
& d.f. & SS & $F$ & $P$ \\
\hline Soil type & 1 & 0.16 & 0.72 & 0.40 \\
Acorn origin & 1 & 4.31 & 19.22 & $<0.05^{*}$ \\
Soil x acorn & 1 & 0.69 & 3.06 & 0.09 \\
Residuals & 32 & 7.17 & & \\
\hline
\end{tabular}


(Ponderosa Pine) in California by Wright (2007). An analysis of 36 years of growth data from a field reciprocal-transplant experiment on serpentine and non-serpentine trees detected serpentine pine ecotypes, but only after 20 years of growth. Jenkinson (1977) conducted a short-term greenhouse seedling reciprocal-transplant study, using the same families of trees as Wright (2007). He found no evidence for serpentine ecotypic variation based on stem height, indicating long time periods might be necessary to unveil patterns of local adaptation in long-lived organisms. This example demonstrates how short-term experiments can be misleading, as the patterns might take many years to be detectable. Wright (2007) did not find final reduced plant stature in the pines from serpentine soils. However, when reduced stature is an adaptation to serpentine, biomass estimates are probably not appropriate to reveal serpentine ecotypes, as they are not necessarily positively correlated with fitness.

The results reported here are based on growth of 8-month-old seedlings in a greenhouse environment, which may or may not be a good surrogate for lifetime fitness. However, they do reveal differences in serpentine and nonserpentine oak populations that could be derived from a process of genetic differentiation and local adaptation. They also suggest the need for further investigation. For a definite test, all the seedlings should be grown until adulthood in their home and foreign environments (in the field) and fitness should be assessed as the ability of individuals to propagate their genes. Such an approach would definitely clarify the existence of oak serpentine local adaptation.

Maternal effects can also explain the results found here. Maternal effects can be defined as the contribution of mother trees to offspring phenotype beyond the equal chromosomal contribution expected from each parent. These can have a substantial influence on an individual's phenotype at early stages. Such effects carry through from germination to early seedling stages, but diminish over time as the offspring's genotype begins to contribute significantly to seedling subsistence (Roach and Wulff 1987). Oak trees produce big seeds that provide substantial resources for germination and early growth, and maternal effects could account for at least part of the results reported in this study. The serpentine and non-serpentine seedling stem height differences detected during transplant onto serpentine and non-serpentine soils might derive from differences in maternal investment across soil types, as trees growing on more fertile non-serpentine soil might produce acorns with more resources inducing better seedling performance. Seedling growth differences right after germination did not derive from differences in soil growth environment, as all plants were grown in the same sand medium. However, as the acorns were excised when seedlings were transplanted, before the endosperm was exhausted, growth response to soil type could be expected to be less influenced by maternal effects. Removing the acorns induced seedlings to depend on their own genotype earlier than normal. Also, analyses on seedling relative growth rate, which showed identical results to 
final seedling height, take possible maternal effects into consideration, since they refer only to the period after the acorn was excised and take into account initial differences in serpentine and non-serpentine performance.

Seedlings showed higher stem heights and relative growth rate when growing on non-sterile non-serpentine soil (table 3 ). This result is not surprising since it is well known that serpentine-adapted plants tend to perform better on non-serpentine soils when not in competition with non-serpentine plant communities (Krukeberg 1950, 1954), suggesting a trade-off between serpentine specialization and competitive ability (Brady et al. 2005). I did not specifically test for competitive ability; however, future experiments could do so by growing seedlings together with serpentine and non-serpentine plant communities in microcosms or field sites.

It was clear that autoclaving soil was an effective way to remove ECM fungi from the soil. This procedure might have undesired consequences, such as changing the soil chemistry (Salonius et al. 1967), which may affect plant growth. However, the shorter stem heights detected on sterile soil compared to non-sterile soil (Table 3) support the long-known fact that ECM fungi positively influence plant growth (Smith and Read 2008). These fungi play an important role in plant nutrition, explaining why seedlings not associated with fungi did poorly when compared to colonized seedlings. It is interesting that soil type was not a significant factor in the analyses of growth in sterile soil alone (Fig. 2, Table 6), suggesting that fungi are equally important for seedling establishment and early growth in serpentine and non-serpentine habitats. The expectation that oak seedlings rely more on ECM fungi when growing on serpentine soils was therefore not validated.

More research is needed to assess the existence of local adaptation in Holm Oak to serpentine soils. Although reciprocal transplants or common garden experiments comparing the fitness of organisms in their original habitats and under different environmental conditions are the most common approaches to detect local adaptation, these methods are difficult to implement for long-lived organisms. Other approaches, like documenting the genetic structure of populations, might provide insightful results. Clarification on the existence of local adaptation patterns is not only of evolutionary interest, but can contribute to applied fields such as conservation and restoration. Documenting diversity and specialization associated with these habitats contributes to delineating priorities when creating conservation programs. It also provides guidelines for effective restoration of serpentine sites, since serpentine ecotypes should be favored when recovering serpentine habitats.

\section{Acknowledgments}

I thank R. Boyd and N. Rajakaruna for editing this special issue; A. Martins for onsite support; C. Aguiar, R. Dias, M. Matos, and A. Pimentel for help in the field; M. Fitzsimons for help with statistical analyses; and D. Eaton, M. Fitzsimons, M. Nelsen, R. Ree, J. Wright, and two anonymous reviewers for comments on earlier drafts. This research was conducted at the Escola Superior Agrária de Bragança 
greenhouse facilities and Biology Department and would not have been possible without the support of their staff. Financial support was available from Fundação Calouste Gulbenkian (Portugal) and the University of Chicago Hinds Fund (USA).

\section{Literature Cited}

Alexander, E., R. Coleman, T. Keeler-Wolf, and S. Harrison. 2007. Serpentine Geoecology of Northern North America. Geology, Soils, and Vegetation. Oxford University Press, New York, NY, USA. 512 pp.

Avis, P.G., D.J. McLaughlin, B.C. Dentinger, and P.B. Reich. 2003. Long-term increase in nitrogen supplies alters above- and below-ground ectomycorrhizal communities and increases the dominance of Russula spp. in a temperate oak savanna. New Phytologist 160:239-253.

Baker, A.J.M., J. Proctor, and R.D. Reeves (Eds.). 1992. The Vegetation of Ultramafic (Serpentine) Soils: Proceedings of the First International Conference on Serpentine Ecology. Intercept, Ltd., Hampshire, UK. 509 pp.

Bradshaw, A.D. 1965. Evolutionary significance of phenotypic plasticity in plants. Advances in Genetics 13:115-155.

Brady, K.U., A.R. Kruckeberg, and H.D. Bradshaw, Jr. 2005. Evolutionary ecology of plant adaptation to serpentine soils. Annual Review of Ecology, Evolution, and Systematics 36:243-266.

Brooks, R.R. 1987. Serpentine and its Vegetation. Dioscorides Press, Portland, OR., USA $454 \mathrm{pp}$.

Charleworth, B. 1994. Evolution in Age-structured Populations. $2^{\text {nd }}$ Edition. Cambridge Univesity Press, Cambridge, UK. 300 pp.

Gardes, M., and T. Bruns. 1996. Community structure of EM fungi in a Pinus muricata forest: Above- and belowground views. Canadian Journal of Botany 74:15721583.

Hartley, J., J.W.G. Cairney, and A.A. Meharg. 1997. Do ectomycorrhizal fungi exhibit adaptive tolerate to potentially toxic metals in the environment? Plant and Soil 189:303-319.

Hedrick, P.W. 1986. Genetic polymorphism in heterogeneous environments: A decade later. Annual Review of Ecology, Evolution, and Systematics 17:535-566.

Kawecki, T.J., and D. Ebert. 2004. Conceptual issues in local adaptation. Ecology Letters 7:1225-1241.

Kruckeberg, A.R. 1950. An experimental inquiry into the nature of endemism on serpentine soils. Ph.D. Dissertation. University of California, Berkeley, CA, USA $165 \mathrm{pp}$.

Kruckeberg, A.R. 1954. The ecology of serpentine soils: A symposium. III. Plant species in relation to serpentine soils. Ecology 35:267-274.

Kruckeberg, A.R. 2002. Geology and Plant Life: The Effects of Landforms and Rock Types on Plants. University of Washington Press, Seattle, WA, USA. 362 pp.

Jenkinson, J.L. 1977. Edaphic interactions in first-year growth of California Ponderosa Pine. USDA Forest Service Research Paper. Pacific Southwest Forest and Range Experiment Station Berkeley, CA, USA. PSW-RO-127. 16 pp.

Jentschke, G., and D. Godbold. 2000. Metal toxicity and mycorrhizas. Physiologia Plantarum 109:107-116.

Panaccione, D.G., N.L. Sheets, S.P. Miller, and J.R. Cumming. 2001. Diversity of Cenococum geophilum isolates from serpentine and non-serpentine soils. Mycologia 93:645-652.

Proctor, J. 1999. Toxins, nutrient shortages, and droughts: The serpentine challenge. Trends in Ecology and Evolution 14:334-335. 
Roach, D.A., and R.D. Wulff. 1987. Maternal effects in plants. Annual Review of Ecology, Evolution, and Systematics 18: 209-235.

Roberts, B.A., and J. Proctor (Eds.). 1992. The Ecology of Areas with Serpentinized Rocks: A World Overview. Kluwer Academic Pulishers, Dordrecht, The Netherlands. $440 \mathrm{pp}$.

Salonius, P.O., J.B. Johnson, and F.E. Chase. 1967. A comparison of autoclaved and gamma-irradiated soils as media for microbial colonization experiments. Plant and Soil 27:239-248.

Sambatti, J., and K. Rice. 2006. Local adaptation, patterns of selection, and gene flow in the Californian Serpentine Sunflower (Helianthus exilis). Evolution 60:696-710.

Schluter, D. 2001. Ecology and the origin of species. Trends in Ecology and Evolution 16:372-380.

Smith, S.E., and D.J. Read. 2008. Mycorrhizal Symbiosis, 3rd Edition. Academic Press, London, UK. 787 pp.

Sokal, R., and F. Rohlf. 1995. Biometry. W.H. Freeman and Company, New York, NY. 887 pp.

Turelli, M., N.H. Barton, and J.A. Coyne. 2001. Theory and speciation. Trends in Ecology and Evolution 16:330-343.

Turesson, G. 1922. The genotypical response of the plant species to the habitat. Heriditas 3:211-350.

Via, S. 2001. Sympatric speciation in animals: The ugly duckling grows up. Trends in Ecology and Evolution 16:381-390.

White, T., T. Bruns, S. Lee, and J. Taylor. 1990. Amplification and direct sequencing of fungal ribosomal RNA genes for phylogenetics. In M. Innis, D. Gelfand, J. Sninsky, and T. White (Eds.). PCR Protocols: A Guide to Methods and Applications. Academic Press, New York, NY, USA.

Williams, G.C. 1966. Adaptation and Natural Selection. Princeton University Press, Princeton, NJ, USA. 307 pp.

Wright, J.W. 2007. Local adaptation to serpentine soils in Pinus ponderosa. Plant and Soil 293:209-217.

Wright, J.W., M.L. Stanton, and R. Scherson. 2006. Local adaptation to serpentine and non-serpentine soils in Collinsia sparsiflora. Evolutionary Ecology Research $8: 1-21$.

Yates, F. 1934. The analysis of multiple classifications with unequal numbers in the different classes. Journal of the American Statistical Association 29:51-66. 